\title{
ОСОБЕННОСТИ УЧЕТА И АНАЛИЗА ЭФФЕКТИВНОСТИ ИСПОЛЬЗОВАНИЯ ОСНОВНЫХ СРЕДСТВ В СФЕРЕ ТЕЛЕКОММУНИКАЦИЙ, МЕДИА И ТЕХНОЛОГИЙ
}

\author{
(C) 2021 Иззука Татьяна Борисовна \\ кандидат экономических наук, доцент, Департамент бизнес-аналитики \\ Финансовый университет при Правительстве Российской Федерации, Россия, Москва \\ E-mail: TBIzzuka@fa.ru \\ (c) 2021 Малышева Татьяна Ивановна \\ студент 4-го курса Факультета налогов, аудита и бизнес-анализа \\ Финансовый университет при Правительстве Российской Федерации, Россия, Москва \\ E-mail: tmalisheva13@yandex.ru
}

В условиях рыночной экономики организации находятся в условиях постоянной жесткой конкурентной борьбы. Целью этой борьбы становится не только максимизация прибыли, но и поддержание их финансовой стабильности и устойчивости. В статье раскрываются особенности учета и анализа эффективности использования основных средств в компаниях, работающих в сфере коммуникаций, медиа и технологий, что обусловлено спецификой деятельности данных компаний и теми задачами, которые они решают в процессе осуществления ими финансово-хозяйственной деятельности.

Компании в сфере телекоммуникаций, медиа и технологий в основном используют большое количество оборудования, необходимого для оказания услуг связи. В процессе ведения бухгалтерского учета имеющееся оборудование у телекоммуникационных компаний учитывается как основные средства. Отдельные элементы оборудования могут добавляться, заменяться, изыматься в ходе различных операций, например, при модернизации и ремонте. На протяжении всего жизненного цикла основных средств, начиная от их строительства или монтажа, и заканчивая ликвидацией и списанием, состав меняется.

Данные хозяйственные операции нужно постоянно учитывать и получать достоверную и исчерпывающую информацию о текущем состоянии объектов основных средств и эффективности их использования. Данная информация является крайне необходимой для многих структурных подразделений телекоммуникационных компаний для принятия оптимальных управленческих решений.

Объекты основных средств в компаниях в сфере телекоммуникаций, медиа и технологий обеспечивают материально-техническую базу оказания ими различных видов услуг. Так, коммутационное оборудование, каналообразующая аппаратура, передаточные устройства непосредственно связаны с процессом передачи сообщений, а здания производственного назначения, сооружения, инструменты обеспечивают необходимые материальные условия для его осуществления. Причем наибольший удельный вес (до 50\%) в структуре основных средств в компаниях в сфере телекоммуникаций составляют машины и оборудование. Расширение и совершенствование материальнотехнической базы обеспечивает повышение уровня конкурентоспособности компаний.

Анализ состава, структуры и динамики основных средств должен проводиться в разрезе их классификационных групп.

Оценку эффективности использования основных средств в телекоммуникационных компаниях необходимо проводить по-разному в зависимости от вида, принадлежности, назначения объектов основных средств, а также их участия в процессе оказания услуг.

Показателями общей эффективности использования основных средств являются показатели фондоотдачи, фондоемкости, фондорентабельности, фондовооруженности, относительной экономии (перерасхода) основных средств. Необходимо уделять внимание факторному анализу фондоотдачи, при котором выясняются причины изменения фондоотдачи, которые зависят от экстенсивности и интенсивности использования основных средств.

Ключевые слова: основные средства, срок полезного использования, первоначальная стоимость, амортизация, коэффициент износа, фондоотдача, фондорентабельность. 


\section{Введение}

Телекоммуникационные компании, как правило, используют большое количество оборудования, необходимого для оказания услуг связи. В процессе ведения бухгалтерского учета имеющееся оборудование у телекоммуникационных компаний учитывается как основные средства. Каждый объект основных средств состоит из частей, которые могут добавляться, заменяться, изыматься в ходе различных операций, например, при модернизации и ремонте.

Состав и структуру основных средств в сфере телекоммуникаций необходимо знать многим подразделениям компании, таким, например, как: финансовой и сервисной службе, службе снабжения, бухгалтерии.

Финансовой службе необходимо анализировать показатели фондорентабельности по видам или группам основных средств во взаимосвязи с географическим расположением объектов основных средств и спецификой их использования. Для службы снабжения крайне важным является процесс принятия грамотных управленческих решений по планированию закупок запчастей.

Сервисная служба должна понимать, какие блоки установлены в оборудовании, и какие чаще всего выходят из строя, и требуют дальнейшего ремонта или замены. В бухгалтерии специалисты должны точно отражать в бухгалтерском и налоговом учете все изменения, связанные с основными средствами.

На протяжении всего жизненного цикла любого объекта основного средства, начиная от его строительства или монтажа и заканчивая ликвидацией и списанием, состав меняется.

При строительстве объектов основных средств происходит формирование их состава. При модернизации и ремонте изменение состава объектов основных средств связано с установкой нового оборудования и заменой оборудования, пришедшего в негодность. При частичной ликвидации основного средства из его состава исключается оборудование, которое относится к ликвидируемой части. При разукрупнении объекта основного средства его состав делится между получаемыми в результате разукрупнения объектами.

Основной признак, который отличает основные средства от других видов активов, заключается в многократном целевом использовании этих средств в производственном цикле. В бухгалтерском учете основные средства при- нято отражать во всех случаях их использования и применения. Отметим, что рациональная организация бухгалтерского учета основных средств - это одна из важнейших предпосылок контроля, наличия и эффектности использования основных средств организации. Необходимо обратить внимание на классификацию основных средств, правильность документального оформления движения основных средств, а также порядок ведения синтетического и аналитического учета основных средств в телекоммуникационных компаниях. Более того, в данных компаниях существуют особенности синтетического и аналитического учета основных средств. Во-первых, учет состава основных средств ведется с момента монтажа основного средства или строительства и до момента частичной или полной ликвидации. Во-вторых, при оказании услуг связи используются агентские схемы, который более детально позволяют изучить детали оказанных услуг. В-третьих, компании ведут раздельный учет доходов и расходов по услугам связи.

Главным источником информации для анализа объектов основных средств организации является первый раздел бухгалтерского баланса, где и отражаются внеоборотные активы - основные средства. Если объект находится в эксплуатации, то основное средство числится на балансе организации. Как правило, объекты основных средств эксплуатируются организацией в течение нескольких месяцев и лет. Однако после длительного периода объекты основных средств изнашиваются и теряют свои первоначальные физические свойства. Именно поэтому в дальнейшем они подвергаются ремонту. Основные средства относятся к внеоборотным активам, поскольку период их оборота соответствует сроку полезного использования, иначе говоря, СПИ, который во много раз превышает срок отчетного периода, который длится 12 месяцев, или нормальный операционный цикл, если он превышает 12 месяцев. В качестве активов основные средства способны приносить экономические выгоды организации в течение отчетного периода и в будущем в течение всего срока полезного использования.

Согласно пункту 7 ПБУ 6/01, основные средства принимаются к учету по первоначальной стоимости. Под первоначальной стоимостью понимается суммарное количество фактических затрат, связанных с приобретением, мон- 
тажом или изготовлением объектов основных средств. К ним можно отнести, во-первых, суммы, уплачиваемые поставщикам и подрядчикам, во-вторых, суммы, уплачиваемые за оказание дополнительных подрядных работ, а также за оказание консультационных услуг. Отметим, что согласно пункту 5 ПБУ 6/01, если стоимость актива составляет больше 40000 рублей, и объект подходит по всем условиям к отнесению к категории «Основные средства», то данные активы можно отнести к основным средствам. Каждая организация вправе установить свой предельный лимит стоимости для признания актива в качестве основного средства, и он может быть ниже 40000 рублей. Данный лимит необходимо также закрепить в учетной политике организации [2]. Согласно п. 4 Приказа Минфина России № $147 \mathrm{H}$, срок полезного использования объекта основного средства, иначе говоря, СПИ - это период использования объекта основных средств, в течение которого он приносит организации экономические выгоды - доход. Для отдельных видов основных средств срок полезного использования может определяться исходя из количества выпускаемой продукции или объема работ в натуральном выражении, который организация ожидает получить в результате эксплуатации данного объекта. Отметим, что в ПБУ 6/01 определён следующий перечень основных средств: здания, сооружения, рабочие и силовые машины и оборудование, измерительные и регулирующие приборы и устройства, вычислительная техника, транспортные средства, инструмент, производственный и хозяйственный инвентарь и принадлежности, рабочий, продуктивный и племенной скот, многолетние насаждения, внутрихозяйственные дороги и прочие соответствующие объекты. Помимо того, в состав основных средств принято относить: капитальные вложения на коренное улучшение земель, капитальные вложения в арендованные объекты основных средств, земельные участки и объекты природопользования.

\section{Практическая часть}

Для более детального анализа динамики, структуры и эффективности использования основных средств была выбрана организация: АО «ТВЦ «Планета», расположенная в г. Оренбург. Основными видами деятельности данной организации являются: создание цифровых развлекательных каналов программ, кинопроизводство, а также деятельность в сфере предоставления услуг телефонной связи. Организация относится к микропредприятию. Среднесписочная численность сотрудников по состоянию на 2020 год - 82 человека. Далее перейдем к анализу основных средств в АО «ТВЦ «Планета». Таким образом, среднегодовая стоимость основных средств организации АО «ТВЦ «Планета» с каждым годом уменьшалась и к концу 2018 года составила 4778 тыс. руб.. Скорее всего, отрицательная динамика основных средств может быть связана с тем, что организация АО «ТВЦ «Планета» применяет по отношению к объектам основных средств следующую политику: она до конца изнашивает имеющиеся у организации объекты основных средств и не закупает новое оборудование.

Далее перейдем к анализу динамики основных средств. Для этого в таблице 1 приведем расчеты следующих показателей динамики за 2018-2020 гг.: базисные и цепные абсолютные приросты среднегодовой стоимости основных средств, а также темпы роста и прироста стоимости основных средств в исследуемой организации.

Исходя из данных, представленных в таблице 1 , следует отметить, что значение среднегодовой стоимости основных средств организации «ТВЦ «Планета», имеет тенденцию к снижению за исследуемый период.

Далее перейдем к более детальному анализу основных средств организации АО «ТВЦ «Планета». Для этого в таблице 2 необходимо выявить их динамику, то есть изменение основных средств во времени путем рассмотрения влия-

Таблица 1. Динамика основных средств АО «ТВЦ «Планета» за 2018-2020 г.г., руб.

\begin{tabular}{|c|c|c|c|c|c|c|c|}
\hline & $\begin{array}{c}\text { Средне- } \\
\text { годовая } \\
\text { Год }\end{array}$ & \multicolumn{2}{|c|}{ Абсолютный прирост, руб. } & \multicolumn{2}{|c|}{ Темп роста,\% } & \multicolumn{2}{|c|}{ Темп прироста,\% } \\
\cline { 3 - 8 } & $\begin{array}{c}\text { ссновных } \\
\text { средств, руб. }\end{array}$ & базисный & цепной & базисный & цепной & базисный & цепной \\
\hline 2018 & 9006000 & - & - & - & - & - & - \\
\hline 2019 & 6656000 & -2350000 & -2350000 & 73,906 & 73,906 & $-26,094$ & $-26,094$ \\
\hline 2020 & 4778000 & -4228000 & -1878000 & 53,054 & 71,785 & $-46,946$ & $-28,215$ \\
\hline
\end{tabular}


Таблица 2. Состав, структура и динамика основных средств АО «ТВЦ «Планета» за 2020 год

\begin{tabular}{|c|c|c|c|c|c|c|c|c|c|c|c|}
\hline \multirow{3}{*}{$\begin{array}{c}\text { Группа } \\
\text { основных } \\
\text { средств }\end{array}$} & \multicolumn{11}{|c|}{2020 год } \\
\hline & \multicolumn{2}{|c|}{$\begin{array}{c}\text { Стоимость на } \\
\text { начало года }\end{array}$} & \multicolumn{2}{|c|}{$\begin{array}{l}\text { Поступило в } \\
\text { течение года }\end{array}$} & \multicolumn{2}{|c|}{$\begin{array}{c}\text { Выбыло в тече- } \\
\text { ние года } \\
\end{array}$} & \multicolumn{2}{|c|}{$\begin{array}{c}\text { Стоимость на } \\
\text { конец года } \\
\end{array}$} & \multicolumn{3}{|c|}{$\begin{array}{c}\text { Изменение } \\
\text { на конец года }\end{array}$} \\
\hline & $\begin{array}{l}\text { тыс. } \\
\text { руб. }\end{array}$ & $\begin{array}{c}\text { удель- } \\
\text { ный } \\
\text { вес в \% } \\
\text { к итогу }\end{array}$ & $\begin{array}{l}\text { тыс. } \\
\text { руб. }\end{array}$ & $\begin{array}{c}\text { удель- } \\
\text { ный } \\
\text { вес в \% } \\
\text { к итогу }\end{array}$ & $\begin{array}{l}\text { тыс. } \\
\text { руб. }\end{array}$ & $\begin{array}{c}\text { удель- } \\
\text { ный } \\
\text { вес в \% } \\
\text { к итогу }\end{array}$ & $\begin{array}{l}\text { тыс. } \\
\text { руб. }\end{array}$ & $\begin{array}{c}\text { удель- } \\
\text { ный } \\
\text { вес в \% } \\
\text { к итогу }\end{array}$ & $\begin{array}{l}\text { тыс. } \\
\text { руб. }\end{array}$ & $\begin{array}{c}\text { удель- } \\
\text { ный } \\
\text { вес, \% }\end{array}$ & $\begin{array}{l}\text { темп } \\
\text { роста, } \\
\quad \%\end{array}$ \\
\hline $\begin{array}{l}\text { Оборудо- } \\
\text { вание }\end{array}$ & 1980 & 49,8 & 4360 & 68,8 & 3450 & 87,1 & 2890 & 45,5 & +910 & $-4,3$ & 145,96 \\
\hline Здания & 1750 & 44,0 & 1410 & 22,2 & 145 & 3,7 & 3015 & 47,5 & +1265 & $+3,5$ & 172,29 \\
\hline $\begin{array}{l}\text { Сооруже- } \\
\text { ния }\end{array}$ & 245 & 6,1 & 563 & 8,9 & 364 & 9,2 & 444 & 7,0 & +199 & $+0,8$ & 181,22 \\
\hline Итого: & 3975 & 100,0 & 6333 & 100,0 & 3959 & 100 & 6349 & 100 & +2374 & - & 159,72 \\
\hline
\end{tabular}

ния каждой группы основных средств на итоговые показатели бухгалтерского баланса АО «ТВЦ «Планета» за 2020 год [7].

Из данных таблицы 2 видно, что стоимость основных средств в компании АО «ТВЦ «Планета» увеличилась к концу года на 2374 тыс. руб. и составила 6349 тыс. руб.. Наибольшее влияние на данное изменение оказало поступление оборудования и зданий. При выбытии объектов основных средств наибольшую долю в выбывших объектах основных средств составило оборудование $-87,1 \%$, а наименьшая доля приходится на здания - 3,7\%.

Далее перейдем к рассмотрению основных базовых показателей, характеризующих движение основных средств. К таким показателям следует отнести: коэффициент обновления, срок обновления и коэффициент выбытия основных средств. Данные для расчета также следует использовать из бухгалтерского баланса организации. В таблице 3 представлены расчеты показателей, характеризующие движение основных средств в АО «ТВЦ «Планета» за 2018-2020 г.г.

Исходя из данных, представленных в таблице 3, следует отметить положительную динамику коэффициента обновления основных средств АО «ТВЦ Планета» за исследуемый период, в то время как коэффициент выбытия на протяжении всего анализируемого периода имел отрицательную динамику. Если значение коэффициента обновления больше, чем коэффициента выбытия в 2019 и 2020 годах, это свидетельствует о совершенствовании материально-технической базы производства, а увеличение стоимости основных средств на конец периода - о ее расширении. Срок обновления основных средств растет, что связано с тем, что на предприятии используется дорогостоящее оборудование, которое полностью изнашивается. Другие показатели, отражающие техническое состояние основных средств,- коэффициент износа и коэффициент годности. Коэффициент износа показывает степень износа объекта основных средств. Данный показатель отражает прямую зависимость от амортизации. Таким образом, чем больше начисляется амортизация, тем больше изнашивается оборудование, и наоборот. Исходя из этого, коэффициент износа рассчитывается путем отношения накопленной амортизации к первоначальной стоимости объекта основных средств. Обратным показателем к коэффициенту износа является коэффициент годности, характеризующий отношение остаточной стоимости основных средств к первоначальной (восстанови-

Таблица 3. Анализ показателей движения основных средств в АО «ТВЦ «Планета» за период 2018-2020 гг., тыс. руб.

\begin{tabular}{|c|c|c|c|}
\hline Показатели & 2018 г. & 2019 г. & 2020 г. \\
\hline Стоимость основных средств на начало периода, тыс. руб. & 5120 & 9006 & 6656 \\
\hline Стоимость поступивших основных средств, тыс. руб. & 160,2 & 158,63 & 124,76 \\
\hline Стоимость выбывших основных средств, тыс. руб. & 98,32 & 87,69 & 54,25 \\
\hline Стоимость основных средств на конец периода, тыс. руб. & 9006 & 6656 & 4778 \\
\hline Коэффициент обновления & 0,018 & 0,024 & 0,026 \\
\hline Срок обновления & 31,96 & 56,77 & 53,35 \\
\hline Коэффициент выбытия & 0,019 & 0,01 & 0,008 \\
\hline
\end{tabular}


тельной) стоимости. Расчеты значений данных показателей представлены в таблице 4.

После проведения расчетов, приведенных в таблице 4, можно отметить следующее: значение коэффициента износа на протяжении исследуемого периода снижалось и на конец 2020 года составило 0,184 . Данный факт означает, что основные средства компании АО «ТВЦ «Планета» находятся в состоянии, пригодном для дальнейшего использования. Ремонт и демонтаж объектов основных средств проходят согласно установленному графику, указанному в техническом паспорте объекта. Значение коэффициента годности, наоборот, имеет положительную динамику, на конец 2020 года его значение составило 0,816. Это свидетельствует о том, что объекты основных средств могут находиться в эксплуатации на протяжении длительного периода.

Показатель фондовооруженности характеризует стоимость основных средств, приходящихся на одного сотрудника. Коэффициент фондовооруженности рассчитывается как отношение среднегодовой стоимости основных средств к среднесписочной численности персонала. Расчеты данного показателя компании представлены в таблице 5 за период 2018-2020 г.г..

На основе данных, представленных в таблице 5 , следует, что значение коэффициента фондовооруженности организации АО «ТВЦ «Планета» за период 2018-2019 г.г. возросло, что связано с уменьшением среднесписочной численности сотрудников. Далее значение коэффициента фондовооруженности снизилось, поскольку среднегодовая стоимость основных средств уменьшилась, но среднесписочная численность персонала осталась по-прежнему на том же уровне. Тем не менее, рост коэффициента фондовооруженности не всегда является положительным фактором. Соответственно, если фондоотдача будет снижаться относительно уровня фондовооруженности, то данный факт будет означать, что организация неэффективно использует свои основные средства. Таким образом, показатели, характеризующие обеспеченность, состояние и движение основных средств компании АО «ТВЦ «Планета», имеют отрицательную динамику.

Далее перейдем к заключительному этапу анализа показателей основных средств в организации АО «ТВЦ «Планета». На данном этапе необходимо провести оценку эффективности следующих показателей, влияющих на увеличение прибыли: фондоотдачи, фондоёмкости и фондорентабельности.

Фондоотдача - это обобщающий показатель, который рассчитывается путем деления выручки за отчетный период к среднегодовой стоимости основных средств за период. Следующий показатель, участвующий в анализе эффективности использования основных средств - фондоёмкость. Фондоёмкость является обратной величиной по отношению к фондоотдаче. Еще один показатель, используемый для оценки эффективности использования основных средств фондорентабельность. Фондорентабельность характеризует прибыль, получаемую с каждого рубля средств, вложенных в основные средства организации.

Расчеты выше перечисленных показателей эффективности использования основных средств представлены в таблице 6.

Исходя из представленных расчетных значе-

Таблица 4. Анализ технического состояния основных средств в АО «ТВЦ «Планета» с 2018-2020 гг.

\begin{tabular}{|l|c|c|c|}
\hline \multicolumn{1}{|c|}{ Показатели } & 2018 г. & 2019 г. & 2020 г. \\
\hline Первоначальная стоимость основных средств, тыс. руб. & 5120 & 9006 & 6656 \\
\hline Сумма начисленной амортизации, тыс. руб. & 1036 & 1802 & 1228 \\
\hline Остаточная стоимость основных средств, тыс. руб. & 4084 & 7204 & 5428 \\
\hline Коэффициент износа & 0,202 & 0,2 & 0,184 \\
\hline Коэффициент годности & 0,798 & 0,8 & 0,816 \\
\hline
\end{tabular}

Таблица 5. Анализ фондовооруженности основных средств в АО «ТВЦ «Планета» в 2018-2020 г.г., руб.

\begin{tabular}{|l|c|c|c|}
\hline \multicolumn{1}{|c|}{ Показатели } & 2018 г. & 2019 г. & 2020 г. \\
\hline Коэффициент фондовооруженности & 60,85 & 81,17 & 58,27 \\
\hline Среднегодовая стоимость основных средств, тыс. руб. & 9006 & 6656 & 4778 \\
\hline Среднесписочная численность персонала & 148 & 82 & 82 \\
\hline
\end{tabular}


Таблица 6. Расчеты показателей эффективности использования основных средств в АО «ТВЦ «Планета» за период 2018-2020 гг.

\begin{tabular}{|l|c|c|c|}
\hline \multicolumn{1}{|c|}{ Показатели } & 2018 г. & 2019 г. & 2020 г. \\
\hline Коэффициент фондоотдачи & 9,733 & 8,517 & 11,504 \\
\hline Коэффициент фондоемкости & 0,103 & 0,117 & 0,087 \\
\hline Коэффициент фондорентабельности & $-1,481$ & $-0,805$ & $-1,490$ \\
\hline
\end{tabular}

ний показателей, содержащихся в таблице 6 следует, что значение коэффициента фондоотдачи АО «ТВЦ «Планета» имело тенденцию снижения с 2018 по 2019 год, а с 2019 по 2020 год наблюдался рост показателя. Что касается динамики фондоемкости, наблюдалась противоположная ситуация: значение коэффициента сначала росло, а потом снижалось.

Далее рассмотрим динамику коэффициента фондорентабельности. Для того, чтобы коэффициент фондорентабельности имел тенденцию роста, необходимо, чтобы значение прибыли росло более быстрыми темпами, чем среднегодовая стоимость основных средств. Значит, АО «ТВЦ «Планета» должна приобретать новые основные средства либо модернизировать старые, чтобы качество предоставляемых услуг компанией улучшалось. Организация должна перенаправить имеющиеся у нее дополнительные денежные средства на модернизацию основных средств либо на приобретение новых, чтобы улучшить фондорентабельность.

\section{Заключение}

На основании результатов проведенного анализа, следует предложить следующие рекомендации по повышению показателей эффективности использования основных средств в организации АО «ТВЦ «Планета». Во-первых, организации следует избавиться от устаревших объектов основных средств. Это будет рациональным мероприятием, поскольку объекты основных средств морально устаревают, изнашиваются, теряют свои технологические свойства. Второй способ улучшения показателей выделение дополнительных денежных средств на покупку новых высокотехнологичных объектов основных средств либо начать модернизацию старых. Модернизация объектов основных средств позволит улучшить результаты функционирования основных средств, а также повысит качество оказываемых услуг. Еще один способ для повышения показателей фондоотдачи - это продажа объектов основных средств, находящихся на складе организации. В связи с тем, что эти объекты никак не используются организацией и лишь хранятся на складах, их стоимость снижается. В том случае, если организация в дальнейшем также не планирует их эксплуатировать, имеет смысл избавиться от них. Например, компания может продать эти объекты с целью получения прибыли.

В условиях современной, динамично развивающейся рыночной экономики основные средства являются главной предпосылкой дальнейшего экономического роста компаний в сфере телекоммуникаций, медиа и технологий. Эффективность оказания услуг в данных компаниях во многом определяется состоянием и функционированием основных средств. Соответственно, в зависимости от того, насколько рационально и эффективно используются основные средства, зависит дальнейшее стратегическое состояние телекоммуникационных компаний. Отсюда вытекает объективная необходимость комплексного совершенствования количественной и качественной структуры, а также использования основных средств в соответствии с уровнем технического прогресса и инновационных форм организации процесса оказания услуг в телекоммуникационных компаниях.

Большая роль должна отводиться аналитической работе, т.к. она предшествует разработке стратегических и тактических планов развития новых технологий в сфере телекоммуникаций. От организации аналитической работы в области основных средств во многом зависят достигнутый в каждой телекоммуникационной компании уровень ее технологий, формы оказания услуг и в конечном итоге эффективность работы компании в целом.

Следует еще раз подчеркнуть, что анализ основных средств позволяет получать информацию для принятия управленческих решений на всех уровнях управления в телекоммуникационных компаниях. Результаты изучения эффективности использования основных средств способствуют оптимизации использования денежных средств за счет снижения неэффективных расходов, а также сокращению затрат по оказанию услуг посредством улучшения использования имеющегося оборудования. 


\section{Библиографический список}

1. Федеральный закон «О бухгалтерском учете» от 06.12.2011 N 402-ФЗ (с изм. и доп.)

2. Приказ Минфина России от 30.03.2001 N 26н (ред. от 16.05.2016) «Об утверждении Положения по бухгалтерскому учету «Учет основных средств» ПБУ 6/01» // СПС Консультантплюс

3. Приказ Минфина России от 08.11.2010 N 94н «Об утверждении Плана счетов бухгалтерского учета финансово-хозяйственной деятельности организаций и Инструкции по его применению» // СПС Консультантплюс

4. Анализ финансовой отчетности: учебное пособие / Л. И. Иванова, А. С. Бобылева.- Москва: КноРус, 2018.$331 \mathrm{c.}$

5. Бухгалтерский финансовый учет и отчетность: учебное пособие / М. Ю. Алейникова, Е. Н. Баранова, О. Е. Качкова.- Москва: КноРус, 2020.-152 с.- Бакалавриат.

6. Иззука Т.Б., Керимова Ч.В. Особенности анализа в сегментах бизнеса.- Практикум.- Издательство Финуниверситета, 2017.-112 с.

7. Никифорова Н. А. Комплексный экономический анализ. Учебник / Москва, Издательство: Компания КноРус (Москва), 2019. Сер. Бакалавриат

8. Никифорова Н.А., Анализ и прогнозирование денежных потоков. Учебник /Н.А.Никифорова, С. Н. Миловидова, Т.Б. Иззука, Е. Н. Баранова, С. В. Филимонов, Т. Н. Фатеева.- Москва, Издательство: Компания КноРус (Москва), 2020. Сер. Бакалавриат и магистратура

9. Храмова Ю.А., Оценка финансового состояния предприятия на основе бухгалтерского баланса // Вектор экономики - 2018-1(19)

10. Носкова М.Д., Сотченко А. В., Чернышова Е. А. Бухгалтерский баланс // Символ науки - 2017 - № 12

11. Финансовый учет и отчетность + Приложение: Тесты: учебник / Г.И.Алексеева, Е. Н.Домбровская, И. В.Сафонова.- Москва: КноРус, 2019.- 440 с.

12. Шнайдер В.В. Теоретические аспекты, понятийный аппарат и задачи анализа финансового состояния // Теория и практика общественного развития - 2019 - № 13 